\title{
MANIFESTAÇÕES AFRO-BRASILEIRAS NO AMAPÁ: A ARTE DO MARABAIXO NO TEMPO PRESENTE
}

\author{
Mônica do Nascimento Pessoa ${ }^{1}$ \\ Raquel Alvarenga de Sena Venera ${ }^{2}$
}

\section{INTRODUÇÃO}

Abre-se um diálogo entre as vidas que se tecem no passado, relacionando-as com possibilidades de uma educação étnico-racial, impulsionada pelo movimento negro afro-brasileiro no tempo presente. Para este artigo, contamos com duas entrevistas, de Danniela Ramose Laura Ramos, afrodescendentes que dançam e cantam o Marabaixo. Suas posições acessam espaços para o debate sobre a implementação da lei federal 10.639103, objetivando romper com as ideias eurocêntricas que ainda se perpetuam nas escolas. Este texto, extrato da dissertação de Mestrado intitulada "Não deixe que morra: O Marabaixo como elo entre patrimônio, memória e educação", apresentada em 2015, incorpora discussões sobre a "colonialidade do saber", e por outro lado, sobre a resistência como impulsionadora de movimentos e performances afro-brasileiras. Importa-nos perceber a dança, com diversos traços da oralidade e da cultura africana, imbricando histórias de ancestralidadee memórias de afrodescendentes como sujeitos históricos.

\section{O SIGNIFICADO DA COLONIZAÇÃO E AS RESISTÊNCIAS DOS COLONIZADOS ATRAVÉS DA MÚSICA E DO CORPO}

"Soou a hora de nós mesmos"

AiméCésaire

\footnotetext{
${ }^{1}$ Doutoranda em História do Tempo Presente no programa de Pós-Graduação em História da Universidade do Estado de Santa Catarina (UDESC). Possui Mestrado em Patrimônio Cultural e Sociedade pela Universidade da Região de Joinville (UNIVILLE), em 2015. Pesquisadora Associada ao Núcleo de Estudos Africanos e Afro-brasileiros (NEAB). E-mail- menina-lilas@hotmail.com.

2 Doutora em Educação pela Universidade Estadual de Campinas (UNICAMP), em 2009. Possui Mestrado em História Cultural pela Universidade Federal de Santa Catarina (UFSC), em 2003. É professora do Mestrado em Educação e do Mestrado em Patrimônio Cultural e Sociedade, ambos da Universidade da Região de Joinville (UNIVILLE), onde é líder do Grupo de Pesquisa Subjetividades e (auto) Biografias. E-mail-raquelsenavenera@gmail.com.
} 
Assim, AiméCésaire fala da violência do colonialismo e do devir dos povos colonizados. Para eleé preciso construir mecanismos de sobrevivência, pois só uma tomada de consciência levaria os povos oprimidos a terem sua história contada por eles mesmos (ANDRADE, 1978, p.10). O Marabaixo é uma manifestação cultural que tem esse poder de contar sobre os processos de territorialidades negras na cidade de Macapá. É uma dança que surge a partir da diáspora africana nas regiões amazônicas no século XVIII, quando através da violência foram forçados ao trabalho escravo para a construção da Fortaleza de São José de Macapá.

Sobre essa presença africana a historiadora Amapaense no estudo sobre o quilombo do Curiaú $^{3}$,explica que, os primeiros africanos a aportarem no Amapá foram os da Guiné Portuguesa, chegaram no ano de 1751, quando da ocupação da região, e eram escravos de famílias provenientes do Rio de Janeiro, de Pernambuco, da Bahia e do Maranhão, trabalhando na cultura do arroz. No entanto, o maior contingente veio a partir de 1765 para a construção da Fortaleza de São José de Macapá, durante o governo do Grão-Pará. Esses escravos morriam de doenças como malária e sarampo, e ainda por acidentes de trabalho (ALBUQUERQUE, 2007, p. 77).

Essas ocupações e empreendimentos da Europa nas colônias revelavam a crueldade que significava a colonização pela via do discurso de "civilização dos povos bárbaros", que não é "nem empresa filantrópica, nem vontade de recuar as fronteiras da ignorância, da doença, da tirania, nem propagação de Deus, nem extensão do direito" (CÉSAIRE, 1978, p. 14). Além disso, significa uma criação humana, e não de alguma potência sobrenatural, o colonizado se torna homem no processo na qual se liberta (FANON, 1961, p.53).Dessa forma, os povos colonizados inventaram várias formas de libertação, seja com sua própria morte, ou através de linguagens, como as danças, os batuques, as religiões, os contos e performances diversas.

O resultado da equação da colonização é igual a coisificação, como diz Aimé Césaire:

Falam-me de sociedades esvaziadas de si próprias, de realizações de doenças curadas, de níveis de vida elevados acima de si próprios. Eu falo de sociedades esvaziadas, de si próprias, de instituições minadas, de terras confiscadas, de

\footnotetext{
${ }^{3}$ Comunidade negra rural, localizada a $8 \mathrm{~km}$ de Macapá. A comunidade é composta por remanescentes de africanos escravizados que vieram para a construção da Fortaleza de São José de Macapá.
} 
religiões assassinadas, de magnificências artísticas aniquiladas, de extraordinárias possibilidades suprimidas (CÉSAIRE, 1978, p.25)

Para resolver essa equação contra o colonizador, Césaire trabalha com o conceito de negritude, ele defende a autodeterminação dos povos para (re) escrever a história por eles mesmos, por suas lutas e resistências. Desse modo, a dança e as cantigas do Marabaixo, com seus ladrões ${ }^{4}$, representam uma das faces da negritude da cidade de Macapá, pois retratam a história de afrodescendentes que com a modernização na década de 1940, foram expulsos do centro da cidade, que deveria se transformar em "cartão postal".

As casas simples, as vivências, as memórias, as plantações, os laços familiares foram desfeitos, como na diáspora atlântica. Os afrodescendentes, moradores da Vila de São José, tiveram que ocupar lugares distantes do centro - Bairros do Laguinho e Favela.

Essa trajetória vai para os ladrões do Marabaixo, caracterizados pelas críticas, sátiras, memórias do cotidiano, dos laços com a terra e com as pessoas que moravam neste lugar. Paul Gilroy (2012, p.164) explica a relação que a música possui com o cotidiano, funcionando como política de libertação, pois,

[...] elas têm procurado papéis que escapam à classificação como prática de legisladores ou intérpretes e, em lugar disso, têm se apresentado como guardiãs temporários de uma sensibilidade cultural distinta e entrincheirada que também tem operado como recurso político e filosófico. [...] Suas síncopes características ainda animam os desejos básicos - serem livres e serem eles mesmos revelados nesta conjunção única do corpo e música da contracultura.

Além de todo esse poder, na denúncia de problemas políticos e sociais, o Marabaixo traz características da oralidade africana: uma canção que retrata um dado momento, de lamento, de vivências, de um cotidiano que remete às histórias dos mais velhos. Ele depende do "Ladrão", feito de um "repente" sobre a vida, e escreve um fato nas memórias compostas nos versos das cantigas. "Um bate lá outro dá cá", entre perguntas e respostas nas rodas, uns falam e outros retrucam, é um diálogo regado a gengibirra ${ }^{5}$, rezas do Divino Espírito Santo e Santíssima Trindade, muita comida e danças para comemorar um reencontro. As cerimônias

\footnotetext{
${ }^{4}$ Letras criadas pelos mais velhos que retratam as vivências dos moradores que foram expulsos da vila de São José de Macapá.

${ }^{5}$ Bebida oferecida aos participantes do Ciclo do Marabaixo, uma mistura de cachaça e gengibre.
} 
são para lembrar quando, na época de vigência da escravidão, seus antepassados foram dispersos pela diáspora africana e espalhados pelos quilombos ${ }^{6}$ existentes pelos quatro cantos da cidade de Macapá. Significa um reencontro das gerações que aprendem e passam adiante uma manifestação cultural que dura por séculos. $E$ que não nasceu aqui. $O$ nome remete à travessia do Atlântico: mar-a-baixo. A letra da música expressa uma forma de contar e cantar a própria vida, entoada no ritmo de caixas que são instrumentos de percussão, confeccionados a partir de um tipo de madeira específica da floresta amazônica e coberta com couro de carneiro e de cobra. Esse instrumento fica nas mãos dos tocadores de caixa, acompanhado da dança de dançadeiras e dançadores, cantados pelos cantadores e cantadoras, sob olhares dos foliões expectadores.

\section{UM JEITO GRIÔ DE CUIDAR DO PASSADO}

Segundo Queiroz (2015), as tradições de diferentes povos africanos englobam elementos religiosos, ritualísticos e transcendentais. Na visão do autor, essas práticas culturais relembram o papel dos Griôs - "depositários das tradições orais africanas, que guardam conhecimento de vida e através das histórias narram fatos passados transmitidos pela tradição" (QUEIROZ, 2015, p. 51). Eles são chamados de mestres por terem o dom da palavra e da memória. Essa atividade de contar histórias é tida como sagrada.

Os griôs assumiram durante muitos séculos diversas funções: eles romperam o esquecimento, exaltaram as tradições, serviram de mediadores em sociedades marcadas por hierarquias, etiquetas, autoridade e reverência, foram portadores das histórias e dos mitos fundadores de regiões e impérios (QUEIROZ, 2014, p. 6).

Os Griôs também possuem influência política e social, intervindo com seus conhecimentos e se responsabilizam por "histórias e genealogias" que envolviam a memória coletiva na África. Por esse motivo, as memórias de africanos não se limitavam a poucos territórios demarcados, mas eram capazes de conectar

\footnotetext{
${ }^{6}$ Segundo Videira (2013, p. 116), no Amapá existe uma estimativa de 580 famílias em 21 comunidades quilombolas, dentre elas: Cunani, no município de Calçoene, Conceição do Macacoari, Lagoa dos Indíos, Mel da Pedreira, Ambé, llha Redonda, Porto do Abacate, Rosa, São José do Mata Fome, São Pedro dos Bois e São Raimundo do Pirativa, em Macapá, entre outros.
} 
diversos povos em processos migratórios pelo continente - indicando a importância desses mestres em narrar histórias como forma de transmitir um passado que possui no presente uma função social. Para Queiroz, através das histórias, o passado "é invocado para se constituir como elemento de justificação, mas jamais imobilismo: a História é viva, o tempo passado e presente é vivido e social, e regulado por certas regras éticas, míticas, religiosas" (QUEIROZ, 2014, p. 54).

Esses mestres "conhecedores, especialistas, ou arquivistas", conhecem a ciência das plantas; em que lidam com as propriedades boas e más de cada espécie, conhecem as terras; entendendo de práticas agrícolas ou medicinais, compreendem sobre psicologia, astronomia e cosmogonias, todas em seu sentido práticos da vida, em que para os conceitos racionalistas podem não fazer sentido. Desse modo, é preciso compreender que se trata da África ocidental, de "uma ciência eminentemente prática que consiste em saber como entrar em relação apropriada com as forças que sustentam o mundo visível e que podem ser colocadas a serviço da vida" (HAMPATÉ BÁ, 2010, p.175).

Algumas aproximações dessas tradições, encontradas principalmente entre os povos mandinga do oeste africano, podem ser relacionadas a elementos constitutivos da dança e dos ladrões do Marabaixo. A autoridade dos mais velhos, que possuem o dom na criação dos versos da música;o fundo social, um apelo às tradições, que remetem às origens dos ancestrais. Além de envolver um sincretismo religioso, com a presença do catolicismo, por meio das festas de São José, padroeiro da cidade de Macapá, unido a religiões de matriz africana, como Candomblé e Umbanda.

A respeito das performances africanas da diáspora, Esiabalrobi (2012, p. 273), poeta, dramaturgo e escritor nigeriano, fazendo um estudo sobre o que os africanos trouxeram consigo, trabalhando principalmente a manifestação carnavalesca nas regiões caribenhas, diz que a música nos lugares em que os povos africanos foram levados "tem servido de ferramenta para interrogar teologias associadas a branquitude e outras manifestações da hegemonia cultural e ocidental". E é nessa relação que se analisam algumas características desta prática cultural do Marabaixo.

Essas práticas, criadas como forma de contestação, para Homi Bhabha são definidos como "entre-lugares", um terreno para se construir subjetividades, para 
se pensar novas identidades, em que as diferenças culturais se fazem através de "estratégias de representação ou aquisição de poder" (BHABHA, 1998, p.20).

São diversos os temas cantados, segundo Videira (2009, p. 142), “as relações amorosas, divergências, insatisfações, sentimentos de "mal querer", separações, comentários maldizentes entre amantes, estão presente em várias cantigas", ao mesmo tempo em que também faz uma represália aos vícios com sátiras, utilizando o bom humor e a criatividade.

Videira (2009, p. 187) menciona ainda a concepção cristã e a cultura do Marabaixo, informando que nem sempre houve uma relação harmoniosa entre elas, pois, em 1948, com a chegada de padres missionários, no governo de Janary Nunes, ocorreu o enfraquecimento dessa manifestação cultural, visto que os católicos proibiam o toque tocassem próximo e dentro da Igreja de São José, já que para eles era coisa do demônio, como relata D. Maria Felícia Cardoso Ramos, de 77 anos, em entrevista registrada por Videira (2009), ao dizer que: "proibiram, nos proibiram de ir a Igreja, eles proibiram esse festejo porque eles diziam que é do demônio" (VIDEIRA, 2009, p. 188).

Em relação a fusão das religiões de matriz africana com o catolicismo, Reginaldo (2009, p. 26), trabalhando sobre as irmandades e devoções de africanos e crioulos na Bahia seiscentista, conceitua o catolicismo negro, afirmando que foi resultado de "uma imposição do regime escravista, permitindo a criação de espaços de culto e reuniões mais ou menos autônomos, como as irmandades e confrarias", se tornando "ponto de concentração e, ao mesmo tempo, um relicário precioso que a igreja ofertou, não obstante ela própria, aos negros, para aí conservar, não como relíquias, mas como realidades vivas" (REGINALDO, apud BASTIDE 1971, p.179). $\mathrm{Na}$ concepção cristã em Macapá, o Marabaixo era macumba, que era "coisa do diabo", como explica Canto (1998 apud Videira, 2009, p. 29):

Essa rotulação fica evidente nas palavras do D. Aristídes Piróvano (primeiro bispo italiano) em entrevista para o Jornal do povo, em dezembro de 1980, quando afirma que "eram muito amigo de Julião Ramos, mas folclore é folclore, religião é coisa séria e não podemos misturar as duas coisas. A igreja não é contrária à diversão do povo, mas não de pode misturar a água benta com o diabo". 
Com a posição de padres da cidade, como o padre Aldenor Benjamim dos Santos, ex-pároco da Igreja São Benedito, essa relação foi se estreitando e o Marabaixo voltou a participar das festas católicas, sendo hoje tradicionalmente organizadas com um sentido sagrado, compondo o "Ciclo do Marabaixo". Para Videira (2009, p. 102), "a festa reúne gerações, histórias de vida e possibilita aprendizado", sendo um momento de reencontro e sociabilidades, incluindo crianças, jovens, adultos e os mais velhos, se encarregando de trazer a dança aos mais novos que, posteriormente, continuarão a dançar essa tradição, transformandoa.

A música aborda uma religiosidade misturada aos passos da dança. No "ladrão" "Aonde tu vai rapaz", ao clamar a São José, padroeiro de Macapá, Raimundo Ladislau, autor deste ladrão, entoa uma problemática social que é o desejo e luta pela moradia e por dignidade, uma questão de pertencimento. Um misto de saudosismo e de indignação, por terem sido expulsos de suas casas.
Aonde tu vai rapaz ${ }^{7}$
Aonde tu vai rapaz
Por esses caminhos sozinho
Eu vou fazer minha morada,
Lá nos campos do Laguinho

A solidão, a dispersão e o abandono dos lares, se traduzia nos ladrões, seguidos com toques de caixa, instrumentos de percussão e o apego a Santíssima Trindade e ao Espírito Santo. Em círculos, os dançantes seguem em passos curtos, para lembrar os pés acorrentados dos escravos africanos, A dança revela um momento de união, alegria e, de fato, uma forma de afirmar sua negritude, um gesto de ruptura ao modelo escravista, pois era comemoração da liberdade.

Destelhei a minha casa

Com a intenção de retelhar

Se a Santa Ingrácia não fica

Como a minha há de ficar

Estava na minha casa

\footnotetext{
${ }^{7}$ Domínio Público.
} 
Conversando com o companheiro

Não tenho pena da terra

Só tenho do meu coqueiro

Ao iniciar o "ladrão" expressando o "caminhar sozinho", o Raimundo reafirma que o processo de mudança, saída do local onde vivia, foi doloroso, permanecendo uma sensação de impotência com a desagregação do grupo. Essa solidão remete ao sentido de grupo, da coletividade e das vivências, que comunitariamente partilhavam. Parece que, ao dispersar as pessoas para um determinado lugar, o grupo se esfacela e, com isso, as memórias e as histórias também se dispersariam, porém não foi isso que aconteceu.

\footnotetext{
A avenida Getúlio Vargas, Tá ficando que é um primor As casas que foram feitas Foi só pra morar doutor
}

Quando o compositor expressa sobre quem vai morar na avenida Getúlio Vargas, configura-se em uma crítica à segregação social existente no estado do Amapá, relegando principalmente os afrodescendentes, com a expulsão de suas casas, dos espaços públicos e do mercado de trabalho, onde assumiam cargos com baixos salários, mantendo uma desigualdade entre as pessoas. Por que esse novo lugar não era lugar de afrodescendentes? Por que só o "doutor"? O que leva o autor, sendo afrodescendente, a pensar que aquele espaço não servia para ele?

\section{POR UMA EDUCAÇÃO ÉTNICO-RACIAL ATRAVÉS DA MÚSICA}

A música é acompanhada de relações sociais, existem mais do que letras ou arranjos nas melodias. Para Adorno "a música de um país tem se tornado uma ideologia política por enfatizar características nacionais", é nessa perspectiva que o Marabaixo se reveste não só em dança, batuques das caixas de tambores, mas como um engajamento político e social, de luta pela memória de afrodescendentes, que resistiram as mudanças com a modernização da cidade de Macapá, e mais que isso, impuseram sua negritude, suas reivindicações, lutaram por espaços que transcenderam suas 
moradas, sua cultura e sua identidade. Para Azevedo (2014, p.215), os negros conseguiram se "enlaçar" na sociedade brasileira, "resistindo a extermínios físico e cultural pelas bordas, periferias, margens e subúrbios das metrópoles brasileiras, permanece de modo mágico-religioso, a recriar todo o mapa geo-histórico das culturas do Brasil". A musicalidade, para as sociedades africanas eram discursos, formas de comunicação. O Marabaixo se enquadra neste aspecto, com diversos trechos das letras das cantigas, com um papel de transgressão.

Os ladrões do Marabaixo revelaram a força desses sujeitos após a escravidão. O papel da música enquanto táticas no embate das lutas cotidianas são modernas porque fogem as lógicas de mercado impostas pelas indústrias culturais, elas são enaltecidas pelo fato de serem artes produzidas por aqueles que se posicionam frente a um grupo racial.A música negra, sua relação de produção com o cotidiano das pessoas e como projeto de emancipação racial devem estar diretamente relacionados (GILROY, 2012, p.159).

O dom de cantar, expressa a subjetividade de quem canta. Atualmente o Marabaixo está sendo ensinado nas escolas, mas que currículo está sendo valorizado?Como podemos romper com as ideias coloniais através dessas práticas? Danniela Ramos, 36 anos, afrodescendente e dançadeira, enfoca esse elo com a educação, e combate o racismo. Danniela revela como foi sua experiência com o racismo, pois, segundo ela, a dança era vista como "coisa de preto e bêbado".São experiências de como conseguiu romper com essas ideias, muitas vezes introduzidas no cotidiano escolar por falta de uma educação anti-racista.

Abaixo alguns trechos de sua entrevista para iniciar uma reflexão sobre a educação que queremos também nas escolas, para a criação de possibilidades múltiplas de lidarmos com a História das Áfricas, nos museus, nos lugares de memórias, como na própria Fortaleza de São José, nas praças, nos filmes e nos livros didáticos.

Danniela narra sua trajetória ao mesmo tempo em que se projeta como sujeito dessa história. Traz uma consciência de que o Marabaixo é lugar de luta, de visibilidade, e possui um discurso militante pela "identidade negra".

Eu aprendi a tocar com a minha vó, e copiava e levava lá pra escola, e dentro da escola eu tinha maior incentivo por parte dos professores. Hoje a gente chama de bullying, mas naquela época a gente não sabia nem o que era isso, porque as pessoas sempre tiveram um conceito deturpado do que é o Marabaixo, achavam que era macumba, que era coisa de preto, de pobre e de bêbado, que na verdade o Marabaixo é sim coisa de preto, mas retrata o cotidiano do povo do Amapá, então é do Amapá como um todo 
independentemente de cor, de raça ou de religião. Na verdade, não é macumba, é Umbanda e Candomblé, que são as religiões de matrizes africanas, mas o Marabaixo não é uma religião, então não tem nenhum envolvimento com Umbanda ou com o Candomblé, é uma manifestação cultural que merece todo 0 respeito independente de religião, mas infelizmente eu sofri muito com esse tipo de preconceito, discriminação e conceito deturpado ${ }^{8}$.

Ela sofreu preconceito na escola, demonstrando que essa cultura não é hegemônica em Macapá, mas que existe um investimento das instituições escolares em levar adiante essa dança, e transformá-la em patrimônio valorizado, respeitado e reconhecido como parte da história do Amapá. Hoje, o Marabaixo é reconstruído e ensinado. Ofertar este conhecimento afro-brasileiro em às escolas simboliza um avanço, pois como exemplo dos embates políticos em torno da memória, o antigo IPHAN (Serviço do Patrimônio Histórico e Artístico Nacional), na década de 30, impunha uma educação branca e européia, com monumentos e conhecimentos dos grandes heróis memoráveis da história brasileira.

Laura Ramos enfatiza a importância de se utilizar a escola para aprender a cultura africana e afro-brasileira e cita a lei como um marco para a difusão desse conhecimento como forma de garantir a equidade e a qualidade da educação. Ela desabafa:

São dez anos de lei e o que precisa? Que se faça valer, que faça acontecer dentro das escolas, porque não está acontecendo [...] Como fazer para que os jovens e as crianças dêem a valorização e o reconhecimento da dança se os professores têm dificuldades de levar o conhecimento histórico aos alunos? O resultado é positivo, a cada convite que temos nós vamos para as escolas, e se torna uma roda de conversa porque as dúvidas são tantas, são muitas perguntas. Muita gente pergunta o que tem a ver o Marabaixo com as religiões de matriz africana, não tem nada a ver, não é uma religião, é uma cultura do Amapá, as religiões é a Umbanda, é o Candomblé, essa é uma dúvida inicial, se o Marabaixo está atrelado ao Candomblé ${ }^{9}$.

Laura externaliza a vontade de lutar por um espaço na educação, reivindicando, por meio da Lei 10.639 , esse espaço como uma abertura para se contar uma história diferente dos africanos e afro-brasileiros, no choque com a educação eurocêntrica e na quebra dos paradigmas por uma educação multirracial.

\footnotetext{
${ }^{8}$ RAMOS, Danniela. Entrevista concedida à Mônica Pessoa. Macapá - AP, 30 de jul. de 2014.

${ }^{9}$ Laura, entrevista citada.
} 
A contribuição da Lei 10.639 foi muito importante, o conhecimento histórico sobre o negro no Brasil era muito pouco, digo que só se mostrava o sofrimento dos africanos escravizados, hoje estamos vivemos um outro momento, temos negros doutores, negros de formação diversas, nunca vamos esquecer nossa história, mas precisamos mostrar para nossas crianças esse novo momento, porque temos muitas crianças negras que não querem ser negro, por conta dessa história de sofrimento, quer queira quer não, nos machucou e nos feriu muito. Mas, diante do momento que a gente vive, precisamos mostrar esse outro lado da história, precisamos apresentar essa mudança e a Lei 10.639. A lei cria a obrigatoriedade para que o contar da nossa história seja continuado dentro da sala de aula, mostrando o antes, o agora e o depois. Porque eu acredito que a tendência é ficar bem melhor. ${ }^{10}$

Sampaio (2011, p. 196) comunga desta ideia quando escreve "Negro na Amazônia: recuperando sua história", em que revela que a maioria das representações mais comuns sobre o mundo do escravo é a "despersonalização do indivíduo" pela visão de todo sofrimento e do desencanto ou os dois lados que versavam violência e rebeldia, não sendo possível perceber que os escravos possuíam relações sociais, uma família e sentimentos longe dos olhos dos seus senhores. É necessário reconhecer a condição humana por cima de toda a ordem escravista, sendo que os escravos eram "passíveis de paixão, ódio, desejos, compreensão, e capazes de entender o momento de agir contra sua condição, negociar, ter reações explícitas, ou não, contra a ordem escravista" (SAMPAIO, 2011, p. 196). Daí a importância de se falar dos afro-brasileiros de um jeito emancipador, que para Laura significa "quebrar os paradigmas, porque a capacidade do negro vai muito além do que imaginamos". Ela dá uma saída: "[...] É preciso que se mostre, que diga, que conte, essa nova história"11

Chagas (2007, p.4) expressa que houve uma espécie de invasão do domínio patrimonial de temas e atores sociais diversos, uma dilatação obrigando o Estado e a política brasileira a desburocratizar e abrir as portas a novos agentes que possuíam patrimônio e uma história a ser estudada, levando-as para as fronteiras do interesse público. Então

as portas do domínio patrimonial foram forçadas. Um número cada vez maior de pessoas (organizadas em grupo ou individualmente) passou a interessar-se pelo campo do patrimônio, não apenas em sua vertente jurídico-burocrática vinculada ao chamado direito administrativo, mas sobretudo, por sua dimensão sociocultural. Forçadas as portas, o domínio patrimonial, ao invés de restringir-se, dilatou-se. E dilatou-se a ponto de

\footnotetext{
${ }^{10}$ Laura, entrevista citada.

${ }^{11}$ Laura, entrevista citada.
} 
transformar-se num terreno de fronteiras imprecisas, terreno brumoso e com um nível de opacidade peculiar (CHAGAS, 2007, p. 4).

Essas portas, definidas aqui como a ida do Marabaixo para as escolas, oferecem tanto instrumentos de propagação quanto, ao mesmo tempo, práticas culturais dos afrodescendentes para o consumo patrimonial. São tentativas de visibilidade positiva, aceitação e lugar no mundo para pessoas que foram - e algumas ainda são - excluídas dos processos patrimoniais convencionais. A escola pode ser um lugar de arranjos políticos, vislumbrando as diferenças, entre a história e a memória, na medida em que ensina, por exemplo, o que é o Marabaixo, levando a coreografia para ser ensinada e explicando a história dos afrodescendentes, que existem em um lugar que não é priorizado pela mídia e também pelas políticas governamentais. Discutir na escola a cultura dos marginalizados historicamente para congregar o currículo na educação formal, foi lido nessa análise como um póscurrículo da diferença, um conceito pensado pelos estudos culturais, grupo de intelectuais engajados que,

estuda e debate questões de classe e gênero, escolhas sexuais e cultura popular, nacionalidade e colonialismo, raça e etnia, religiosidade e etnocentrismo [...] Processos de significação e disputas entre discursos, políticas de identidade e da diferença, estética e disciplinaridade, comunidades e imigrações, xenofobia e integrismo, cultura juvenil e infantil, história e cultura global (CORAZZA, 2010, p. 103).

Pensar em um currículo com foco nas diferenças também parece um desafio. Um monumento que guarda uma história de séculos é capaz de ser transformado em um currículo? E uma dança? E os ladrões do Marabaixo? Essas manifestações culturais podem ter funções didáticas fora dos muros escolares?

Uma dança que vai além de passos coreografados, é história que se comunica nas escolas, nos trapiches, na Fortaleza. Por se fazer dançando, cantando e festejando a história e a memória as quais são compartilhadas, estão também vivas, são conflitos, sensações, sofrimentos. Desde o coqueiro retirado do fundo de um quintal, como o próprio ladrão menciona - "não tenho medo da minha casa, só tenho do meu coqueiro" - até a construção do espaço urbano, das ruas para os "doutô", porque as ruas que são feitas são para os doutores, mas o Marabaixo "militante" que vai para escolas ensina que os caminhos trilhados em busca de 
liberdade, educação, igualdade são construídos pelas mãos de quem viveu e pode, através de suas memórias, manter a luta viva, criando a cada dia motivos e ações para enfrentar as diferenças, transformando o Marabaixo em uma arma potente por meio do ensino da história dos africanos e afro-brasileiros no enfrentamento da opressão e do racismo no Amapá e no Brasil.

Essa educação que ensina os passos da dança nas escolas, para debater questões que quebram o tabu e o silêncio para falar de racismo e igualdade, coloca em cheque que somos diferentes,e que a cor da pele influência nas oportunidades e no cotidiano das pessoas, evidencia desse modo, que os conhecimentos podem ser produzidos fora dos centros hegemônicos. A colonialidade do saber revela que além da violência e injustiças geradas pelo colonialismo, há todo um legado de conhecimento que nos impede de perceber que há um mundo além-europeu, que existem povos com identidades, valores, riquezas e conhecimentos próprios (PORTO-GONÇALVES, 2005, p.03).

Uma educação que rompa com os padrões normativos europeus é uma necessidade urgente, como fazer com que as crianças e jovens conheçam sua história, e como saber se posicionar e lutar diante das ações racistas? De acordo com Boaventura (2010, p.84), a colonialidade se sustenta quando se impõe classificações raciais e étnicas para a diferenciação da população, agindo de forma material e subjetiva, para enaltecer apenas um padrão de poder, branco e europeu, se traduzindo em racismo e exclusão de tudo que é inverso. Dessa forma, a colonialidade naturaliza as relações e experiências dos povos colonizados, tendo como verdade uma única racionalidade, a eurocêntrica, imposta como símbolo da modernidade (BOAVENTURA, 2010, p.86).

As epstemes eurocêntricas subestimam a existência de diversas formações sociais em vários cantos do mundo, porém existe todo um legado epistemológico fora das linhas europeias, de povos que tinham suas religiões, impérios e civilizações, que passaram a constituir um mundo, diferente do imaginário construído pelo discurso colonial.

o pensamento está em todos os lugares, onde os diferentes povos e suas culturas se desenvolveram e, assim, são múltiplas as epistemes com seus muitos modos de vida. Há assim com seus muitos mundos de vida, das águas, da terra, do fogo, do ar, dos homens (PORTO-GONÇALVES, 2005, p. 03). 
É preciso traçar novos mapas, novas rotas marítimas que não foram estudadas, expor novas histórias do descobrimento, falar de Áfricas é não de uma só África, colocar em evidencia questões polêmicas, ultrapassar barreiras, e através do conhecimento, construir histórias que contemplem os povos colonizados, os diferentes, os marginalizados, os excluídos.

\section{REFERENCIAS}

ALBUQUERQUE. Eliane. Cheiros e batuques do museu: Construindo conceitos poéticos no quilombo do Curiáu. Revista Negro e Educação - Linguagens, educação, resistências, políticas públicas, São Paulo. V.4, p. 73-93, 2007.

AZEVEDO, Amailton. As manifestações afro-brasileiras: Arte, literatura e religiosidade. In: CARDOSO, Paulino. RASCKE, Karla. Formação de Professores: produção e difusão de conteúdos sobre história e cultura afro-brasileira e africana. Florianópolis: DIOESC, 2014.

BÂ, Amadou Hampâté. Amkoullel, o Menino fula. Tradução: Xina Smith Vasconcellos. São Paulo: Casa das Áfricas/Palas Athena. São Paulo, 2003.

BHABHA, Homi. O local da Cultura. Belo Horizonte: Editora UFMG, 1998.

CESÁIRE, Aimé. 0 discurso sobre o colonialismo. Porto: Poveira, 1971.

CHAGAS, Mário. Casas e portas da memória e do patrimônio. Em questão, comunicação e informação. Porto Alegre. V. 13, n. 2, p. 207-224, Jul/dez. 2007.

CORAZZA, Sandra. Diferença pura de um pós-currículo. In: LOPES, Alice. MACEDO, Elizabeth (organizadoras). - 3 ed. São Paulo: Cortez, 2010 - (série cultura, memória e currículo).

ESIABA, Irobi. O que eles trouxeram consigo: Carnaval e persistência da performance estética africana na diáspora. Projeto História. São Paulo, n. 44, p. 273-293, jun. 2012.

FANON, Frantz. Os condenados da terra. 1 reimpressão. Juiz de Fora. UFJF, 2005.

GILROY, Paul. O Atlântico Negro: modernidade e dupla consciência. São Paulo: Ed.34; Rio de Janeiro: Universidade Candido Mendes. Centro de Estudos Afro-Asiáticos, 2001.

GONÇALVES, Porto. A colonialidade e cabo a rabo: o hemisfério ocidental no horizonte consitual da modernidade. In: LANDER, Edgard (org.). MIGNOLO, Walter.Acolonialidade do saber: Eurocentrismo e Ciências sociais. Perspectivas Latino-Americanas. Buenos Aires; CLACSO, 2005. 
QUEIROZ, Igor. Formas africanas de lidar com o passado: Oralidade, mitos, ritos, tradições. In MORTARI, Claúdia (Org). Curso de Introdução aos Estudos e da Diáspora. 2014, Florianópolis: UDESC.

REGINALDO, Lucilene. Irmandades e devoções de africanos e crioulos na Bahia setecentista: histórias e experiências atlânticas. Stockholm Rewiew of Latin American Studies. Issue, n. 4, Maio. 2009, p. 25-35.

SAMPAIO, Patrícia. O fim do silencio: presença negra na Amazônia. Negro na Amazônia Afro-Ásia. v. 45, p.195-200, 2012.

SANTOS, Boaventura de Sousa; MENESES, Maria Paula. (Orgs.) Epistemologias do Sul. São. Paulo; Editora Cortez. 2010. 637páginas. Epistemologias do Sul.

VIDEIRA, Piedade Lino. Marabaixo, dança afrodescendente: Significando a identidade étnica do negro amapaense. Fortaleza: Edições UFC, 2009. 